Davidson, S., and Watson, C. W. (1956). Neurology (Minneap.), 6. 235 .

Fischer-Williams, M. (1961). Lancet, 1, 394.

Garvie, J. M. (1961). Ibid., 1, 395.

Gastaut, H., Régis, H., Bostem, F., and Beaussart, M. (1960). Rev. neurol., 102. 533 .

- Trevisan, C., and Naquet, R. (1958). Electroenceph. clin. Neurophysiol.. 10.194.

Hutchison, J. H., Stone, F. H., and Davidson, J. R. (1958). Lancet. 1. 243

Ismay, G. (1958). Ibid., 1, 376.

Kiloh, L. G., and Osselton, J. W. (1961). Clinical Electroencephalography, p. 38. Butterworths, London.

Klapetek, J. (1959). Electroenceph. clin. Neurophysiol., 11, 809.
Lagergren, J., and Hansson, B. (1960). J. Amer. med. Ass., 172, 475.

Lange, L. S. (1961). Electroenceph. clin. Neurophysiol., 13, 490.

Madden, T. B. (1961). Lancet, 1, 395.

Marshall, C., Walker, A E., and Livingston, S. (1953). Arch. Neurol. 'Psychiat. (Chic.), 69, 760.

Mawdsley, C. (1961). Lancet, $1,190$.

Mundy-Castle, A. C. (1953). Electruenceph. clin. Neurophysiol., $5,1$.

Pallis, C., and Louis, S. (1961). Lancet, 1, 188.

Rao, K. S., and Prichard, J. S. (1955). J. Pediat., 47, 619.

Richter, H. R. (1960). Rev. neurol., i03, 283.

Walter, V. J., and Walter, W. Grey (1949). Electroenceph. clin. Neurophysiol., 1. 57.

\title{
RADIO-OLEIC-ACID AND RADIOTRIOLEIN TESTS IN DIFFERENTIAL DIAGNOSIS OF STEATORRHOEA
}

BY

\author{
A. E. DAVIS,* M.A., M.B., B.S., B.Sc., M.R.C.P. \\ Assistant to the Nuffield Professor of Clinical Medicine \\ From the Nuffield Department of Clinical
}

\author{
J. BADENOCH, D.M., F.R.C.P. \\ Consultant Physician, United Oxford Hospitals
}

There is general agreement that the most reliable way of diagnosing steatorrhoea is by direct estimation of the faecal fat, but the methods used are time-consuming and often difficult to arrange in routine hospital practice.

The most important causes of steatorrhoea in this country are idiopathic steatorrhoea, coeliac disease, and failure of the pancreas. In the advanced case these can be differentiated readily, but in the early stages diagnosis is often difficult.

In recent years, following the lead of Malm, Reemtsma, and Barker (1956), a number of workers have administered radioactive fats and fatty acids to patients with steatorrhoea in the hope that a test could be devised which would distinguish between the various causes of steatorrhoea, the rationale being that in idiopathic steatorrhoea neither the fatty acid nor the fat would be absorbed adequately owing to the generalized intestinal mucosal defect, whereas in steatorrhoea due to failure of the pancreas fatty acid would be absorbed normally but the absorption of neutral fat would be reduced.

We have administered a labelled fat (radiotriolein) and a labelled fatty acid (radio-oleic acid) to normal subje is and to patients with steatorrhoea in an attempt to develop a reliable screening procedure, capable of being performed on out-patients, which would not only detect the presence of steatorrhoea but would be of value in differential diagnosis.

\section{Selection of Patients}

The following groups were chosen for study.

Normal Subjects.-These were 12 people attending the department of physical medicine for minor disabilities after accidents. None had a history of any gastroenterological complaint.

Patients with Pancreatic Steatorrhoea.-Four patients were investigated. All had a marked steatorrhoea which ranged from 25 to $100 \mathrm{~g}$. of fat excreted in the faeces per day. The jejunal mucosa in each case was histologically normal, and the pancreatic aetiology was confirmed by (1) the absence of pancreatic enzymes in the aspirated duodenal fluid, (2) the presence of pancreatic calcification as shown by a plain $x$-ray film of the abdomen, and (3) a diabetic glucose-tolerance test.
Patients with Idiopathic Steatorrhoea.-These were seven patients who had a typical history, an abnormal jejunal mucosa, and had responded to treatment with a gluten-free diet.

\section{Methods}

The methods we have used for administering the radiotriolein and the radio-oleic acid are given in detail because reports of the reliability of these two tests have varied in the literature. Relatively small changes in method have produced marked changes in the results obtained, both in normal subjects and in patients with steatorrhoea.

Earlier workers using radiotriolein and oleic acid have placed greater reliance on the estimation of the radioactivity in the blood than on the estimation of the radioactivity in the faeces (Baylin, Sanders, Isley, Shingleton, Hymans, Johnston, and Ruffin, 1955; Malm et al., 1956; Beres, Wenger, and Kirsner, 1957).

On theoretical grounds the estimation of the level of radioactivity in the blood as an index of absorption is a poor substitute for actual estimation of faecal radioactivity. The level in the blood is influenced by the rate of gastrie emptying, the speed of passage through the small bowel, the absorptive capacity of the small bowel, the rate of clearance of the lipid from the blood, the rate of metabolism of the lipid, and the consequent distribution of iodine throughout the extracellular fluid and its subsequent excretion by the kidney. Moreover, Grossman and Jordan (1958) have shown that low levels of radioactivity in the blood do not always exclude the presence of steatorrhoea as assessed by chemical analysis of the faeces.

It has been stated that the radioactivity excreted in the urine during the first 24 hours after oral administration of the radiotriolein is a reliable method for the diagnosis of steatorrhoea (Walker, Stewart, Morgan, and McKie, 1960). While the effect of different rates of fat absorption and metabolism would tend to be minimized by counting the radioactivity in 24-hour specimens of urine instead of in the blood, it is hard to conceive that any method based on the measurement of urinary radioactivity could be as accurate in the diagnosis of steatorrhoea as the actual measurement of the radioactivity in the faeces. 
In this study we have not measured the radioactivity in the blood. In the initial stages an attempt was made to estimate the radioactivity in the urine, but the method was abandoned because of the wide range of values obtained.

\section{The Radiotriolein Test}

The criteria for a successful method of administering radiotriolein are: (1) that the test procedure is safe for the patient and an excessively large amount of radioactivity is not used; (2) that the results obtained correlate well with the chemical analysis of faecal fat ; and (3) that the emulsion of radioactive fat used is stable and can be stored.

The radioiodinated triolein was obtained from the Radiochemical Centre, Amersham, where it was prepared by using olive oil, B.P. grade, and reacting this with iodine monochloride ${ }^{131} \mathrm{I}$ in a mixture of carbon tetrachloride and acetic acid. The quantity of iodine monochloride ${ }^{131}$ l used was sufficient to saturate about $30 \%$ of the double bonds present as indicated by the iodine value.

We mixed $2 \mathrm{ml}$. of the radioactive oil containing 1 millicurie with $98 \mathrm{ml}$. of inert oil (B.P. grade) for half an hour, using a magnetic stirrer. A primary emulsion was made by mixing the oil with $25 \mathrm{~g}$. of powdered acacia for one minute, then adding $50 \mathrm{ml}$. of water as quickly as possible and stirring briskly for at least 20 minutes. The resultant oil-in-water emulsion was diluted to 1 litre by the intermittent addition of increasing amounts of water while brisk stirring was continued. The result was an oil-in-water emulsion which could be pipetted accurately, could be washed from glass surfaces easily, and had a specific activity of $1 \mu \mathrm{c} / \mathrm{ml}$.

Then $200 \mathrm{ml}$. of this emulsion was placed in a separate container, the rest, containing $800 \mu \mathrm{c}$, being stored under adequate protection. The stability of this emulsion was checked by repeated tests over a period of four to five weeks. The working emulsion, which was kept in a refrigerator, was taken out every fourth day and four separate aliquots were pipetted into cardboard cartons and made up to $200 \mathrm{ml}$. with water and counted individually in the arrangement used for faecal counting (see below). On each occasion the activity counted in the separate aliquots was constant.

In carrying out the radiotriolein test it is customary to give potassium iodide before and during the test procedure to prevent the thyroid gland taking up any of the radioactive iodine. However, we found that a high proportion of patients suffered reactions to the potassium iodide. In mild cases the reactions were likened to the prodromata of the common cold-a running nose, profuse lacrimation, sore throat, and generalized headache. In more severe cases there was swelling of the parotid and other salivary glands, severe retro-orbital headache, and a feeling of constriction in the throat. Originally the amount of potassium iodide used was $10 \mathrm{gr}$. $(0.65 \mathrm{~g}$.) three times a day, as suggested by Walker et al. (1960). This was later reduced to $3 \mathrm{gr}$. $(0.2$ g.) three times a day, although reactions were still obtained and these were eliminated only when an antihistamine (isothipendyl hydrochloride (" nilergex S.A.") $12 \mathrm{mg}$. b.d.) was administered simultaneously. Therefore, for two days before and three days after the emulsion was given the patients received potassium iodide $3 \mathrm{gr}$. $(0.2 \mathrm{~g}$.) three times 2 day together with isothipendyl $12 \mathrm{mg}$. b.d. That this amount of iodide was sufficient was checked by scanning thyroid and thigh with standard surface-scanning equipment, utilizing a sodium iodide crystal $2.5 \mathrm{~cm}$. in diameter with a suitable lead collimator. In every patient the surface counts obtained over the thyroid were no greater than those obtained over the anterior thigh.

The patients came to hospital fasting and were given a breakfast consisting of about $50 \mathrm{~g}$. of fat in the form of scrambled eggs, bread, butter, and a cup of tea. They then drank from a glass beaker $25 \mathrm{ml}$. of the working active emulsion, which had been diluted to $200 \mathrm{ml}$. with milk. The beaker was rinsed repeatedly with either milk or water, depending on the patient's choice. After the test dose the patients were asked to collect their faeces in waxed cartons for the next three days. These cartons were counted individually in a multitube GeigerMüller ring $12 \mathrm{~cm}$. in diameter and $5.5 \mathrm{~cm}$. long.

When urinary radioactivity was measured separate 24-hour collections were counted in a specially prepared multitube Feiger-Müller ring using tubes $24 \mathrm{~cm}$. long by $2.5 \mathrm{~cm}$. in diameter.

\section{Radio-oleic-acid Test}

The method for the preparation of the radio-oleic acid differed fundamentally from reported methods in that it was also given in the form of an emulsion.

The labelled oleic acid was supplied diluted in olive oil and $2 \mathrm{ml}$. of this solution was taken and treated in exactly the same fashion as the radiotriolein, so that the two procedures could be standardized. Other methods reported in the literature have made use of capsules, a dangerous procedure which involves the repeated handling of 1 or $2 \mathrm{ml}$. of a solution of high specific activity. At first we were afraid that the oleic acid in the form of an emulsion would cause diarrhoea or have an objectionable taste, but preliminary tests on a group of laboratory personnel proved our fears to be unjustified.

A most important advantage of our method over any method using capsules is that $25 \mathrm{ml}$. of an oil-in-water emulsion of relatively low specific activity is used, whereas in other methods 1 or $2 \mathrm{ml}$. of an oily solution of extremely high specific activity is pipetted into small capsules. The possibility of technical errors in pipetting small quantities of oil of a high specific activity is much greater than when dealing with large volumes of a freely running emulsion of low specific activity.

\section{Estimation of Faecal Fat}

The faecal fat was measured by the method of van de Kamer, Huinink, and Weyers (1949).

\section{Results}

Radiotriolein Test.-This was performed on 12 normal subjects (Table I). In none was the amount of the oral dose of radioactivity excreted in the faeces greater than $1 \%$ (the results in the table are expressed to the nearest $0.5 \%$ ). Nine patients with steatorrhoea were studied (Table II), and all except one excreted in the faeces $2 \%$ or more of the administered radioactivity. The exception was a patient of considerable interest. He was a man of 30 with a history dating back to childhood. His disease appeared to be undergoing a spontaneous remission. At the time of the test he was free from symptoms. The excretinn of fat in his faeces (8 g./day) was just outside the accepted upper limit of normal of $7 \mathrm{~g}$./day, but, even so, his jejunal mucosa showed the pattern of subtotal villous atrophy. 
The results of the estimation of radioactivity in the urine after the oral administration of radiotriolein (Tables I and II) are far too variable to be used as a screening test for the diagnosis of steatorrhoea, as the loss of fat in the stool has to be greatly in excess of normal before the excretion of radioactivity in the urine drops below the normal range.

TaBle I.-Results of Radiotriolein Test in Normal Subjects

Percentage of Orally Administered Radjoactivity Excreted in

\begin{tabular}{c|c|c|c|c}
\hline $\begin{array}{c}\text { Faeces } \\
\text { (to Nearest }\end{array}$ & \multicolumn{4}{|c}{ Urine (24 Hours) } \\
$0.5 \%$ ) & 1st & 2nd & 3rd & Total \\
\hline 1.0 & 79 & 9 & 2 & 90 \\
1.0 & 68 & 12 & 2 & 82 \\
1.0 & 74 & 18 & 3 & 95 \\
0.5 & 64 & 20 & 5 & 89 \\
0 & 76 & 9 & 2 & 87 \\
0 & 65 & 18 & 3 & 86 \\
0 & 47 & 15 & 2 & 64 \\
0.5 & 76 & 9 & 2 & 87 \\
1.0 & 57 & 24 & 3 & 84 \\
0.5 & 72 & 10 & 1 & - \\
0.5 & - & - & - & - \\
1.0 & - & - & & \\
\hline
\end{tabular}

TABLE II.-Results of Radiotriolein Test in Patients with Steatorrhoea

\begin{tabular}{|c|c|c|c|c|c|c|}
\hline \multirow{3}{*}{$\begin{array}{c}\text { Aetiology } \\
\text { of } \\
\text { Steator- } \\
\text { rhoea }\end{array}$} & \multirow{3}{*}{$\begin{array}{c}\text { Faecal } \\
\text { Fat } \\
\text { (g./Day) }\end{array}$} & \multicolumn{5}{|c|}{$\begin{array}{c}\text { Percentage of Orally Administered Radioactivity } \\
\text { Excreted }\end{array}$} \\
\hline & & \multirow{2}{*}{ Faeces } & \multicolumn{4}{|c|}{ Urine (24 Hours) } \\
\hline & & & 1st & 2nd & 3 rd & Total \\
\hline $\begin{array}{c}\text { Idiopathic } \\
\text { ", } \\
\text { ", } \\
\text { ", } \\
\text { Pancreatic } \\
\text {," }\end{array}$ & $\begin{array}{r}8 \\
13 \\
14 \\
22 \\
23 \\
21 \\
49 \\
49 \\
100\end{array}$ & $\begin{array}{r}1 \\
2 \\
2 \\
12 \\
13 \\
17 \\
55 \\
65 \\
68\end{array}$ & $\begin{array}{l}77 \\
65 \\
\text { Co } \\
= \\
37 \\
21 \\
21 \\
23\end{array}$ & $\begin{array}{c}\text { ined } \\
21 \\
\text { ed } 97 \\
-5 \\
21 \\
10 \\
8 \\
6\end{array}$ & $\begin{array}{r}25 \\
2 \\
97 \\
1 \\
5 \\
2 \\
3 \\
3\end{array}$ & $\begin{array}{l}102 \\
88 \\
97 \\
\\
63 \\
33 \\
32 \\
32\end{array}$ \\
\hline
\end{tabular}

Radio-Oleic-Acid Test.-The results obtained with this test in normal subjects were similar to those obtained with the radiotriolein test (Table III). Whereas no normal subject excreted in the faeces more than $1 \%$ of the oral dose of radioactivity, the amounts excreted in the urine were variable. The test was performed on four patients with pancreatic steatorrhoea (Table IV). It was found that between 3 and $7 \%$ of the oral dose was excreted in the faeces. Seven other patients with steatorrhoea, not of pancreatic origin (Table V), excreted from 6 to $55 \%$ of the radioactivity in the faeces. An eighth patient, the one referred to in the previous section with minimal disease, excreted only $1 \%$ of the administered radioactivity in the faeces.

TABLE III.-Results of Radio-oleic-acid Test in Normal Subjects

\begin{tabular}{|c|c|c|c|c|}
\hline \multicolumn{5}{|c|}{ Percentage of Orally Administered Radioactivity Excreted in } \\
\hline \multirow{2}{*}{$\begin{array}{c}\text { Faeces } \\
\text { (to Nearest } \\
0.5 \%)\end{array}$} & \multicolumn{4}{|c|}{ Urine (24 Hours) } \\
\hline & 1st & 2nd & 3 rd & Total \\
\hline $\begin{array}{l}1.0 \\
0.5 \\
1.0 \\
1.0 \\
0.5 \\
1.0\end{array}$ & $\begin{array}{l}65 \\
75 \\
75 \\
57 \\
61 \\
-\end{array}$ & $\begin{array}{r}15 \\
16 \\
9 \\
22 \\
19 \\
-\end{array}$ & $\begin{array}{r}3 \\
4 \\
-5 \\
4 \\
-\end{array}$ & $\begin{array}{l}83 \\
95 \\
84 \\
84 \\
-\end{array}$ \\
\hline
\end{tabular}

TABle IV.-Results of Radio-oleic-acid Test in Patients with Pancreatic Steatorrhoea

\begin{tabular}{c|c}
$\begin{array}{c}\text { Faecal Fat } \\
\text { (g./Day) }\end{array}$ & $\begin{array}{c}\text { Percentage of Orally Administered } \\
\text { Radioactivity Excreted in Faeces }\end{array}$ \\
\hline 25 & 4 \\
29 & 3 \\
49 & 6 \\
100 & 7
\end{tabular}

TABle V-Results of Radio-oleic-acid Test in Patients with Steatorrhoea Not of Pancreatic Origin

\begin{tabular}{|c|c|c|c|}
\hline \multicolumn{2}{|c|}{ Aetiology of Steatorrhoea } & Faecal & $\begin{array}{l}\text { Percentage of Orally } \\
\text { Administered Radioactivity } \\
\text { Excreted in Faeces }\end{array}$ \\
\hline $\begin{array}{cc}\text { Idiopathic } & \ldots \\
\text { Post-gastrectomy } \\
\text { Idiopathic } & \ldots \\
,, & \ldots \\
\text {, } & \ldots \\
, & \ldots \\
, & \ldots\end{array}$ & $\begin{array}{ll}\cdots & \cdots \\
\cdots & \cdots \\
\cdots & \cdots \\
\cdots & \cdots \\
\cdots & \cdots \\
\cdots & \cdots \\
\cdots & \cdots\end{array}$ & $\begin{array}{r}8 \\
9 \\
11 \\
13 \\
14 \\
23 \\
23 \\
25\end{array}$ & $\begin{array}{r}1 \\
21 \\
6 \\
6 \\
10 \\
15 \\
55 \\
7\end{array}$ \\
\hline
\end{tabular}

Consecutive use of Radiotriolein and Radio-OleicAcid Tests.-Both these tests were performed on four patients - two with pancreatic steatorrhoea and two with idiopathic steatorrhoea. The contrast in the pattern of absorption can be seen from Table VI. Both the patients

TABLE VI.-Results of Consecutive Radiotriolein and Radiooleic-acid Tests

\begin{tabular}{|c|c|c|c|}
\hline \multirow{2}{*}{$\begin{array}{l}\text { Aetiology of } \\
\text { Steatorrhoea }\end{array}$} & \multirow{2}{*}{$\begin{array}{l}\text { Faecal Fat } \\
\text { (g./Day) }\end{array}$} & \multicolumn{2}{|c|}{$\begin{array}{c}\text { Percentage of Orally Administered } \\
\text { Radio-activity in Faeces }\end{array}$} \\
\hline & & Radiotriolein & Radio-oleic Acid \\
\hline $\begin{array}{c}\text { Pancreatic } \\
\text { Idiopathic } \\
, \quad \text {. }\end{array}$ & $\begin{array}{r}49 \\
100 \\
14 \\
23\end{array}$ & $\begin{array}{r}65 \\
68 \\
2 \\
13\end{array}$ & $\begin{array}{r}6 \\
7 \\
10 \\
15\end{array}$ \\
\hline
\end{tabular}

with pancreatic steatorrhoea excreted large quantities of the radiotriolein in the faeces, but the excretion of radio-oleic acid was low. The two patients with idiopathic steatorrhoea, although they had a less severe steatorrhoea, excreted greater quantities of radio-oleic acid in the faeces.

\section{Discussion}

The use of ${ }^{131}$ I-labelled triolein as a test for fat absorption involves two main assumptions: firstly, that the ${ }^{131} \mathrm{I}$ triolein is a typical fat which is digested and absorbed in the same manner as the usual food fats; and, secondly, that the iodine tag remains firmly attached to the fat while it is in the bowel lumen.

It has been shown that ${ }^{131}$ I-labelled triolein when injected intravenously is treated in the same way as the natural fat tripalmitin (van Handel and Zilversmit, 1957), and Hoffman (1953) has shown that if ${ }^{131} I$ oleic acid is administered orally to rabbits it is incorporated normally into the adipose tissue.

The stability of the preparation has been demonstrated by Balint, Pendower, and Ramsey (1960), who incubated the labelled triolein for periods of up to three and a half hours with the digestive secretions of the upper alimentary tract. In this study time limits for the incubations were set at approximately the periods for which the fat would be in contact with the particular digestive enzymes in vivo digestion. Other workers, such as A. E. Cox (personal communication, 1961), have shown that some of the radioactive iodine may be split off from the radiotriolein after incubations for periods of up to three to four days, although both the smallness of the breakdown and the unphysiological times involved suggest that this is of little importance during in vivo digestion.

The good correlation between the results of chemical analysis of the fat in the stools and the excretion of radiotriolein that we have obtained are in contrast with the results of Pimparkar, Tulsky, Kalser, and Bockus (1961) and of Cox. The explanation may lie in the difference in the method of preparing and giving the test emulsion. 
The tables show that the radio-oleic-acid test is as useful in the diagnosis of steatorrhoea as the more traditional radiotriolein test. In addition it provides a valuable aid in the differential diagnosis of the cause of the steatorrhoea. The patients with idiopathic steatorrhoea (excluding the special case referred to above) excreted between 6 and $55 \%$ of the dose of radioactive oleic acid in the faeces. None of the four patients with pancreatic steatorrhoea excreted more than $7 \%$. The two that excreted 6 and $7 \%$ respectively were both in the late stages of the disease ; one had diabetes mellitus and the other calcification of the pancreas, and neither presented a diagnostic problem. The other two were early cases, and the involvement of the pancreas would have been overlooked if it had not been possible to intubate them and measure the pancreatic enzymes in the duodenal juice.

In the four patients-two with pancreatic steatorrhoea and two with idiopathic steatorrhoea-in whom both the radiotriolein test and the radio-oleic-acid test were performed (Table VI) the results were as expected. In the two with pancreatic steatorrhoea excretion of radioactivity in the faeces after the administration of radiotriolein was much greater than when radio-oleic acid was given. In contrast, the two patients with idiopathic steatorrhoea excreted $10-15 \%$ of the radiooleic acid, while the excretion of radiotriolein was much less than in the two patients with pancreatic involvement.

\section{Summary}

A reliable method for the administration of radiotriolein and radio-oleic acid is described.

In 12 normal subjects the faecal excretion of radiotriolein was $1 \%$ or less of the administered dose, whereas in seven patients with idiopathic steatorrhoea it ranged from 1 to $55 \%$, and in two patients with pancreatic steatorrhoea it was 65 and $68 \%$.

The faecal excretion of radio-oleic acid was $1 \%$ or less in six normal subjects, in four patients with pancreatic steatorrhoea it was between 3 and $7 \%$, while in eight patients with steatorrhoea not of pancreatic aetiology it ranged from 8 to $25 \%$.

The results of the estimation of the radioactivity in the urine after the oral administration of radiotriolein and radio-oleic acid were too variable to be of any help in the diagnosis of steatorrhoea.

The value of the radio-oleic-acid test is stressed. It would appear that this test may be more helpful than the radiotriolein test in the diagnosis of steatorrhoea.

In detecting cases of steatorrhoea due to pancreatic failure, the radio-oleic-acid test is of value both when administered alone and when used in conjunction with the radio-triolein test.

We are grateful to the physicians and surgeons of the United Oxford Hospitals for their kindness in allowing us to study their patients ; to Dr. H. T. Howat, of Manchester Royal Infirmary, for permission to study patients under his care ; and to Professor L. J. Witts for his helpful advice and criticism.

\section{REFERENCES}

Balint, J., Pendower, J., and Ramsey, N. W. (1960). Clin. Sci., 19. 321

Baylin, G. J., Sanders, A. P., Isley, J. K., Shingleton, W. W. Hymans, J. C., Johnston, D. H., and Ruffin, J. M. (1955) Proc. Soc. exp. Biol. (N.Y.) 89, 51

Beres, P., Wenger, J., and Kirsner, J. B. (1957). Gastroenterology, 32. 1.

Grossman, M. I., and Jordan, P. H. (1958). Ibid., 34, 892

Hoffman, M. C.'(1953). J. Lab. clin. Med., 41, 521

Malm, J. R., Reemtsma, K., and Barker, H. G. (1956). Proc. Soc. exp. Biol. (N.Y.), 92, 471.

Pimparkar, B. D., Tulsky, E. G., Kalser, M. H., and Bockus, H. L. (1961), Amer. J. Med., 30, 927.

van de Kamer, j. H., Huinink, H. ten B., and Weyers, H. A. (1949) J. biol. Chem.. 177, 347.

van Pandel, E., and Zilversmit, D. B. (1957). Fed. Proc., 16 131.

Walker, W. F., Stewart, W. K., Morgan, H. G., and McKie, J (1960). Brit. med. J., 1, 1403.

\section{PINEAL ENLARGEMENT, WITH HYPERNATRAEMIA, HYPOKALAEMIC ALKALOSIS, AND THYROTOXICOSIS}

BY

\author{
A. KENNEDY, M.B., Ch.B. \\ Lecturer in Pathology \\ D. KILSHAW, F.I.M.L.T. \\ Chief Technician
}

N. C. R. W. $\begin{gathered}\text { REID, } \\ \text { Medical Registrar }\end{gathered}$

AND

\section{W. H. TAYLOR, M.A., D.M., M.R.C.P. Chemical Pathologist}

From the Department of Pathology, University of Liverpool; the Royal Infirmary; and the Department of Chemical Pathology, Liverpool

Experimental work in animals suggests that adrenoglomerulotrophin, a hormone controlling the secretion of aldosterone by the adrenal cortex, is elaborated in the pineal gland and neighbouring areas of the brain (Farrell, 1959). The hormone has been tentatively identified as 1-methyl-6-methoxy-1,2,3,4-tetrahydro-2carboline (Farrell and McIsaac, 1961). The association of pineal enlargement with many of the features of primary hyperaldosteronism in the case described below is thus of interest, and it is believed that this is the first case of its kind to be reported.

Methods.-Urinary 17-ketosteroids were determined by the method recommended by the Medical Research Council Committee (1951) and 17-hydroxycorticosteroids by a modification of the method of Moxham and Nabarro (1956). Aldosterone was isolated by the method of Mattox and Lewbart (1959) and its concentra. tion determined in the Aminco-Bowman spectrofluorimeter after coupling with salicyloyl hydrazide (Kilshaw, 1962).

\section{Case History}

A woman aged 58 was admitted to hospital complaining of palpitations of two weeks' duration, of a dry tongue for one week, and of general weakness over the previous four days. Her past health had been good, except that at the age of 46 she was treated for thyrotoxicosis with iodine. There had been no subsequent recurrence of thyrotoxic symptoms.

Inquiry revealed that she had had difficulty in eating solid food because of dryness of the tongue and throat. but that previously her appetite had been excellent. She had felt thirsty, had been drinking more than usual, and had been passing "plenty of urine." She had not been vomiting. She expressed a preference for warm weather, but did not sweat unduly. Two or three formed stools were passed daily. She had probably lost $7 \mathrm{lb}$. $(3.2 \mathrm{~kg}$.) in weight over the previous month. 